\title{
Corrigendum
}

\section{Frosting on the cake: pictures on food packaging bias serving size - CORRIGENDUM}

\author{
John Brand, Brian Wansink and Abby Cohen
}

First published online 26 April 2017

DOI: 10.1017/S1368980016000458. Published online by Cambridge University Press, 30 March 2016.

All experimental analyzes were checked after statistical inconsistencies were identified in the reporting of the results. Statistical corrections are reported below. No findings or conclusions are impacted by these corrections. The size of the effect, however, is reduced in Experiment 3. For simplicity, the corrected results and associated figures and tables are reported in full in this corrigendum. The authors wish to apologize for the errors.

\section{Original text and correction:}

\section{Study 1: Corrected Table 1}

\begin{tabular}{|c|c|c|c|c|c|c|c|c|}
\hline \multirow[b]{2}{*}{ Cake brand } & \multicolumn{4}{|c|}{ Cake only } & \multicolumn{4}{|c|}{ Cake with frosting } \\
\hline & $\begin{array}{l}\text { Avg. calories } \\
\text { per serving }\end{array}$ & $\begin{array}{l}\text { Avg. calories } \\
\text { shown }\end{array}$ & $\begin{array}{c}\text { Avg. } \\
\text { change }\end{array}$ & $t$ test & $\begin{array}{l}\text { Avg. calories } \\
\text { (frosting) }\end{array}$ & $\begin{array}{l}\text { Total calories } \\
\text { shown }\end{array}$ & $\begin{array}{l}\text { Avg. } \\
\text { change }\end{array}$ & $t$ test \\
\hline $\begin{array}{l}\text { Betty Crocker } \\
\quad(n 20)\end{array}$ & $264 \cdot 00$ & $225 \cdot 70$ & $-38 \cdot 30$ & $10 \cdot 08^{\star \star \star}$ & $309 \cdot 22$ & 534.91 & 270.91 & $11 \cdot 30^{\star \star *}$ \\
\hline $\begin{array}{l}\text { Duncan Hines } \\
\quad(n 18)\end{array}$ & $246 \cdot 67$ & $287 \cdot 49$ & $40 \cdot 82$ & $4.05^{\star \star \star}$ & $475 \cdot 13$ & $762 \cdot 62$ & $515 \cdot 95$ & $12 \cdot 42^{\star \star \star}$ \\
\hline Pillsbury ( $n$ 13) & 259.23 & $210 \cdot 00$ & $-49 \cdot 23$ & $43 \cdot 69^{\star \star \star}$ & 275.56 & 485.56 & $226 \cdot 33$ & $200 \cdot 84^{\star \star \star}$ \\
\hline All $(n 51)$ & $256 \cdot 67$ & 243.50 & $-13 \cdot 16$ & 1.93 & $359 \cdot 19$ & $602 \cdot 70$ & 346.03 & $13 \cdot 97^{\star \star \star}$ \\
\hline
\end{tabular}

${ }^{\star \star *} P<0.001$.

\section{Corrected Study 1 Results:}

Study 1 results are shown in Table 1 . When cake calculations were based solely on the cake, cake boxes did not display significantly more calories than what is recommended $(t(50)=1 \cdot 93, P=0 \cdot 06)$, a decrease of $5 \cdot 13 \%$. Breaking down by brand, only Duncan Hines exaggerated the number of calories shown, displaying $16 \cdot 5 \%$ more $(t(17)=4 \cdot 05, P<0 \cdot 001)$. Both Betty Crocker and Pillsbury displayed fewer calories than what is recommended, $14.5 \%$ and $19 \cdot 0 \%$, respectively $(t(19)=10 \cdot 08, P<0 \cdot 001)$ and $t(12)=43 \cdot 69, P<0 \cdot 001)$.

In contrast, when frosting was included in the calculation, all cake mix boxes exaggerated the amount of calories associated with a serving size. On average, cake mix containers displayed $134.82 \%$ more calories than what is recommended $(t(50)=13.97$, $P<0 \cdot 001)$. Duncan Hines brand displayed 209.17\% more calories $(t(17)=12 \cdot 42, P<0 \cdot 001)$; Betty Crocker displayed $102 \cdot 61 \%$ more calories $(t(19)=11 \cdot 30, P<0 \cdot 001)$; and Pillsbury depicted 87.31\% more calories $(t(12)=200 \cdot 84, P<0 \cdot 001)$.

\section{Study 2: Corrected Table 2}

\begin{tabular}{lccc}
\hline & No mention of frosting & 'Frosting not included on the nutritional labelling' & Control: cake no frosting \\
\hline Cake calories selected & & & \\
Betty Crocker & 591.60 & 433.07 & 411.67 \\
Duncan Hines & 594.53 & 438.27 & $402 \cdot 80$ \\
Average & 593.07 & $435.67^{\star}$ & $407 \cdot 23$ \\
\hline
\end{tabular}

Note: There was neither a significant difference between cake brands, nor a significant interaction between cake brand and condition type.

${ }^{*}$ Calorie estimations for cake with frosting images were significantly lower when there was a corresponding message than not $(P<0.001)$. There was no significant difference in calorie estimations between the control group and the text group. 


\section{Corrected Study 2 Results:}

Study 2 results are shown in Table 2 . Group estimations were entered into a $3 \times 2$ mixed-model ANOVA. There was a significant main effect of condition. Calorie estimations were lowest for those who were shown a cake package with no frosting $(F(2,42)=4.04, P=0.025)$. There was no difference in calorie estimations between the cake mix brands $(478.78 v .478 .53 \mathrm{kcal}$; $F(1,42)=0.001, P=0.994)$ and there was also no significant interaction between the groups $(F(2,42)=0 \cdot 030, P=0 \cdot 976)$. Planned comparisons showed that of the participants who were shown cake with frosting packages, the number of calories estimated by people who were told no additional information was higher than by those who were told that frosting was not included on the nutritional labelling $(593.07 v .435 .67 \mathrm{kcal} ; t(28)=2 \cdot 10, P=0.04)$. Interestingly, there was no difference in calorie estimations between those who were shown packages with cake and frosting, but told that frosting was not included, and those who were shown packages with cake only $(407.23 v .435 \cdot 67 \mathrm{kcal} ; t(28)=0 \cdot 37, P=0 \cdot 710)$.

\section{Study 3: Corrected Figure 1}

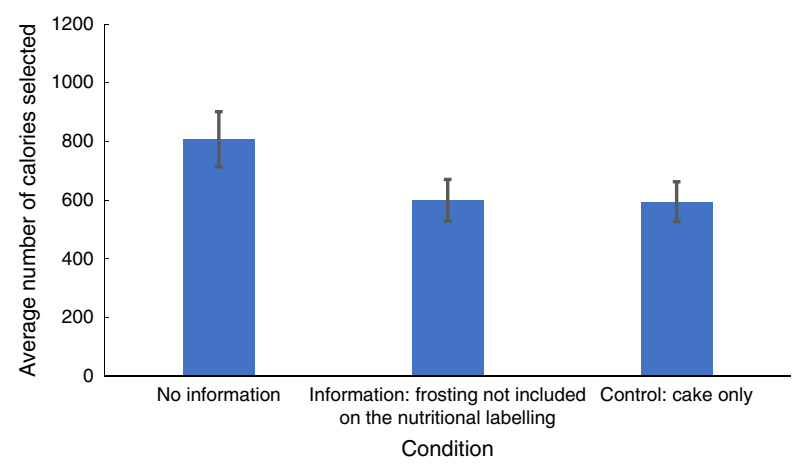

Figure 1 Mean number of cake calories served by participants ( $n$ 72) for each condition in Study 3 . Error bars represent the $95 \%$ confidence intervals. Participants downsized portions when told frosting was not included on the nutritional labelling ('calories' $=\mathrm{kcal} ; 1 \mathrm{kcal}=4 \cdot 184 \mathrm{~kJ}$ )

\section{Corrected Text:}

Results for Study 3 are shown in Fig. 1. There was a significant main effect of condition $(F(2,69)=5 \cdot 92, P=0 \cdot 004)$. Intended serving size was lowest for participants who were shown a cake box showing a piece of cake without frosting. $t$ Tests showed that when participants were shown a piece of cake with frosting, intended serving size was lower if the packaging contained the message 'frosting not included on the nutritional labeling' $(808 v .600 \cdot 00 \mathrm{kcal} ; t(46)=2 \cdot 73$, $P=0 \cdot 009)$, a decrease of approximately $208 \mathrm{kcal}$.

Similar to Study 2, there was no significant difference in intended serving size between participants who saw cake with no frosting and participants who saw cake with frosting and the phrase 'frosting not included on the nutritional labeling' (595 $v$. $600 \mathrm{kcal} ; t(46)=0 \cdot 065, P=0.948)$.

\section{Experiment 4 results:}

Please read 575 as 573; and 453 as 455 